\title{
Response of the Northern Hemisphere sea ice to greenhouse forcing in a global climate model
}

\author{
Larissa Nazarenko, ${ }^{1,2}$ James Hansen, ${ }^{1}$ Nikolai Tausnev, ${ }^{1,3}$ Reto Ruedy ${ }^{1}$ \\ ${ }^{1}$ NASA Goddard Institute of Space Studies, New York, NY 10025, U.S.A. \\ ${ }^{2}$ Center for Climate Systems Research, Columbia University, New York, NY 10025, U.S.A. \\ ${ }^{3}$ Rutgers University, New York, NY 10025, U.S.A.
}

\begin{abstract}
The Q-flux Goddard Institute of Space Studies (GISS) global climate model, in which an atmospheric general circulation model is coupled to a mixed-layer ocean with specified horizontal heat transports, is used to simulate the transient and equilibrium climate response to a gradual increase of carbon dioxide $1 \%$ per year increase of $\mathrm{CO}_{2}$ to doubled $\mathrm{CO}_{2}$ ). The results indicate that the current GISS model has a high sensitivity with a global annual warming of about $4^{\circ} \mathrm{C}$ for doubled $\mathrm{CO}_{2}$. Enhanced warming is found at higher latitudes near sea-ice margins due to retreat of sea ice in the greenhouse experiment. Surface warming is larger in winter than in summer, in part because of the reductions in ice cover and thickness that insulate the winter atmosphere from the ocean. The annual mean reduction of sea-ice cover due to doubled $\mathrm{CO}_{2}$ is about $30 \%$ for the Northern Hemisphere. The $\mathrm{CO}_{2}$ experiment has a $70 \%$ reduction of sea-ice area and 55\% thinning of ice in August in the Northern Hemisphere. Noticeable reduction of sea-ice cover has been found in both historical records and satellite observations. The largest reduction of simulated sea-ice extent occurs in summer, consistent with observations.
\end{abstract}

\section{INTRODUGTION}

The continued accumulation of greenhouse gases in the atmosphere is one of many reasons for global climate modifications. In the last few years there has been an intensification of interest in climate change, partly because of extreme events, including summer droughts in the United States and Europe and milder winter conditions in the regions of cold climate. General circulation models are a prime tool for studying the current climate and the changes to it due to an increase of greenhouse gases. Results from various mathematical models of the climate system show that warming of the troposphere as a consequence of increasing carbon dioxide $\left(\mathrm{CO}_{2}\right)$ can be expected, assuming that all other components of the system remain unchanged (Hansen and others, 1984, 1988; Washington and Meehl, 1984; Wetherald and Manabe, 1986; Wilson and Mitchell, 1987; Rind and others, 1989; Schlesinger and Zhao, 1989; Manabe and others, 1991; Meehl and others, 1993).

Numerous simulations of the possible climatic changes which could occur under equilibrium $\left(2 \times \mathrm{CO}_{2}\right)$ greenhouse conditions have been carried out by several groups (Hansen and others, 1984, 1988; Washington and Meehl, 1984; Wetherald and Manabe, 1986; Wilson and Mitchell, 1987; Rind and others, 1989; Schlesinger and Zhao, 1989; Manabe and others, 1991; Meehl and others, 1993; Gordon and Hunt, 1994). Greenhouse gas experiments have been reviewed by Schlesinger and Mitchell (1987), Mitchell (1989) and Houghton and others (1990).

The experiment discussed here explores simulated climatic change at equilibrium in a $2 \times \mathrm{CO}_{2}$ experiment. A three-dimensional NASA Goddard Institute of Space Studies (GISS) atmospheric general circulation model (Hansen and others, 1997) coupled to a mixed-layer ocean and thermodynamic sea-ice model is used. The mixedlayer ocean model allows sea-surface temperature (SST) to change as a result of atmosphere-ocean heat-flux exchange but with implicitly prescribed climatological ocean heat transport (the so-called "Q-flux" approach). These coupled atmosphere-mixed-layer ocean models have been extensively used for $\mathrm{CO}_{2}$ increase experiments (Wilson and Mitchell, 1987; Hansen and others, 1988; Gordon and Hunt, 1994) and paleoclimate simulations (Kutzbach and Gallimore, 1988; Mitchell and others, 1988).

The purpose of this paper is to examine the equilibrium response of the Northern Hemisphere climatology in the NASA GISS coarse-grid global coupled climate model. We illustrate simple aspects of interannual and seasonal variability in the model and observations by looking at geographic patterns of surface air temperature, sea-level pressure, precipitation and sea-ice extent for the Northern Hemisphere. The current climate $\left(1 \times \mathrm{CO}_{2}\right.$ : control run $)$ is compared with the new equilibrium climate obtained after a gradual increase of carbon dioxide (an exponential transient increase of $1 \%$ per year until the $\mathrm{CO}_{2}$ amount doubled). We compare the Northern Hemisphere sea-ice areas and thickness to observed ice-area data (NSIDG, 1997) and central Arctic ice-thickness data (Rothrock and others, 1999), as well as the control and $\mathrm{CO}_{2}$ results of seaice quantities for the Northern Hemisphere and central Arctic. We also discuss seasonal changes of the Arctic seaice extent under doubled $\mathrm{CO}_{2}$ climate forcing. 

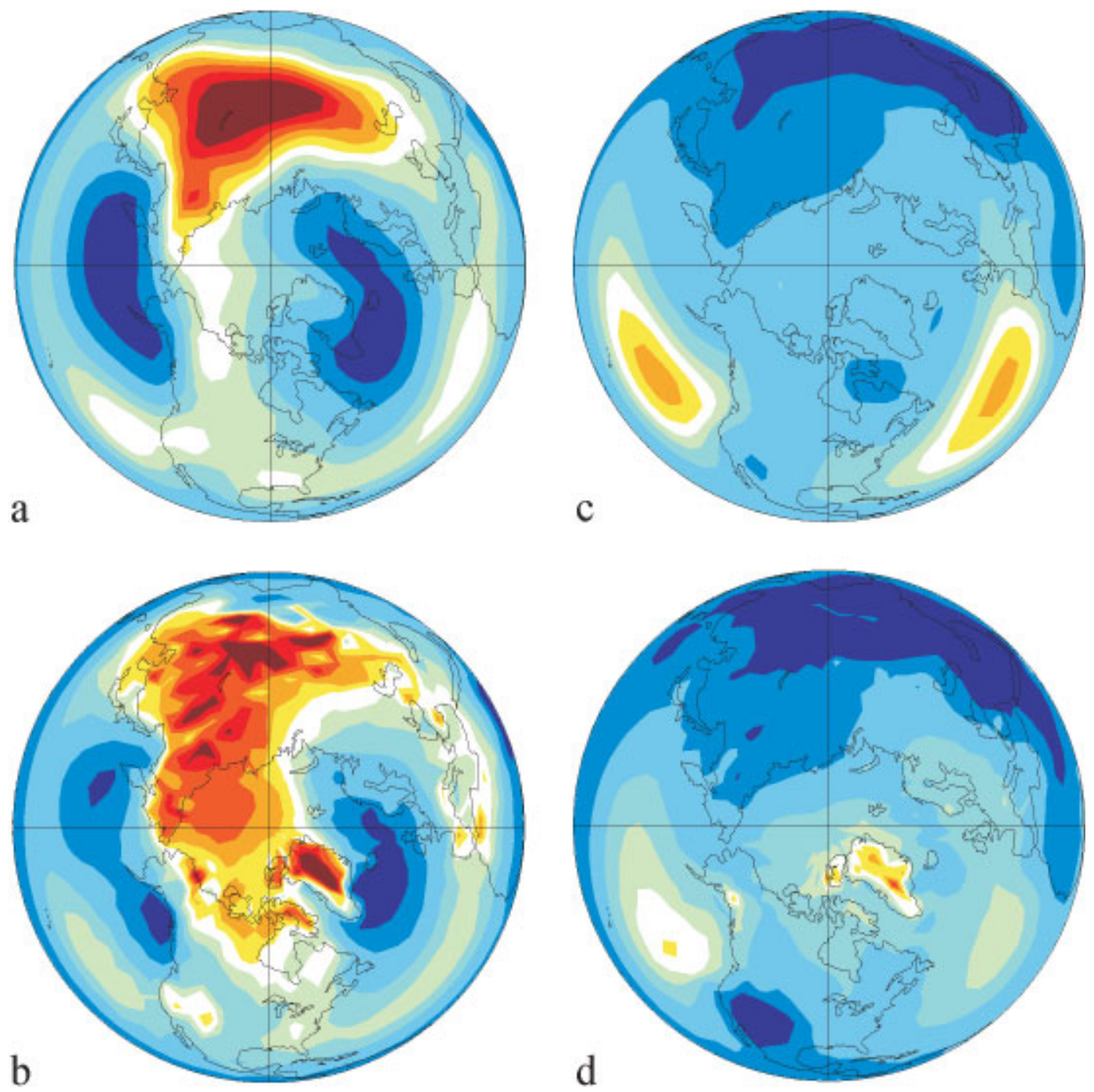

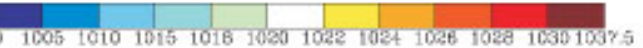

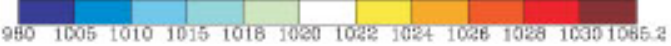

Fig. 1. Sea-level pressure: (a) DfFobserved (Shea and others, 1990); (b) DfF modeled minus control run; (c) $77 A$ observed (Shea and others, 1990); (d) 77 A modeled minus control run.

\section{THE GOUPLED MODEL}

The coupled atmosphere--mixed-layer ocean model used in this study is the Q-flux version of the GISS global climate model described by Hansen and others (1997), with some modifications of the atmospheric model. The horizontal resolution of the model is set as $4^{\circ}$ latitude $\times 5^{\circ}$ longitude both in the atmosphere and in the ocean. In this model, an improved four-layer thermodynamic sea-ice model is employed and the atmosphere has 12 vertical layers with the three added layers in the upper troposphere and stratosphere. The Q-flux ocean model (Hansen and others, 1984; Wilson and Mitchell, 1987) is one member of a hierarchy of ocean representations, ranging from observed ocean temperatures to fully prognostic dynamical models that are being attached to the same atmospheric model. The ocean has a monthly-varying mixed-layer depth and specified horizontal transport of heat, thus permitting SST to be simulated. The mixed-layer oceanic transports were computed in a preliminary model run which used the observed monthly mean SSTdistribution.

Starting from the state reached at the end of the preliminary integration, the mixed-layer model was integrated further, allowing the temperature of the mixed-layer ocean to change thermodynamically. Calculations of changes in thickness of the four-layer ice and snow layers are based on energy balances at the various interfaces (Parkinson and Washington, 1979); snow is accumulated at the rate computed in the atmospheric model. The albedo of snow ice depends on surface temperature, snow and ice thickness and snow age. The melting begins from the top and bottom surfaces of the snow-ice slab. If the computed top or bottom surface temperatures are $>0{ }^{\circ} \mathrm{C}$, it is set to $0^{\circ} \mathrm{C}$, and the excess heat accumulated at the snow-ice surfaces is used to melt the snow ice. If the snow ice melts completely, the heat flux from the atmosphere goes to the warming of the ocean surface.

Two 150 year integrations of the coupled model were performed. The $\mathrm{CO}_{2}$ concentration remains unchanged in the first integration (the control run). In the second integration the atmospheric concentration of carbon dioxide increased at a rate of $1 \%$ per year for 70 years. The initial conditions for both integrations have realistic seasonal and geographical distributions of SST and sea ice, with which both the atmospheric and oceanic components of the model are nearly in equilibrium. This equilibrium condition for the control run was obtained by separate integration of the 
a
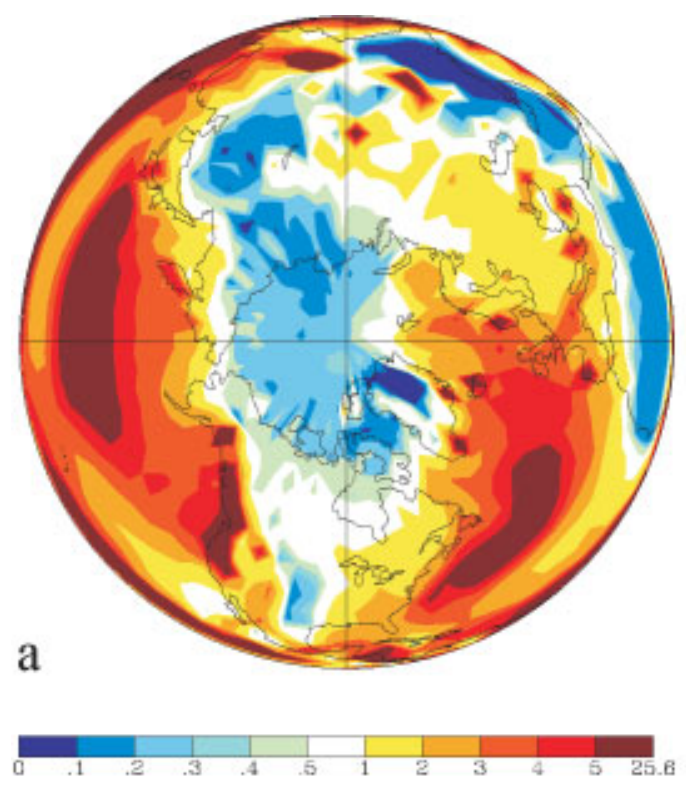
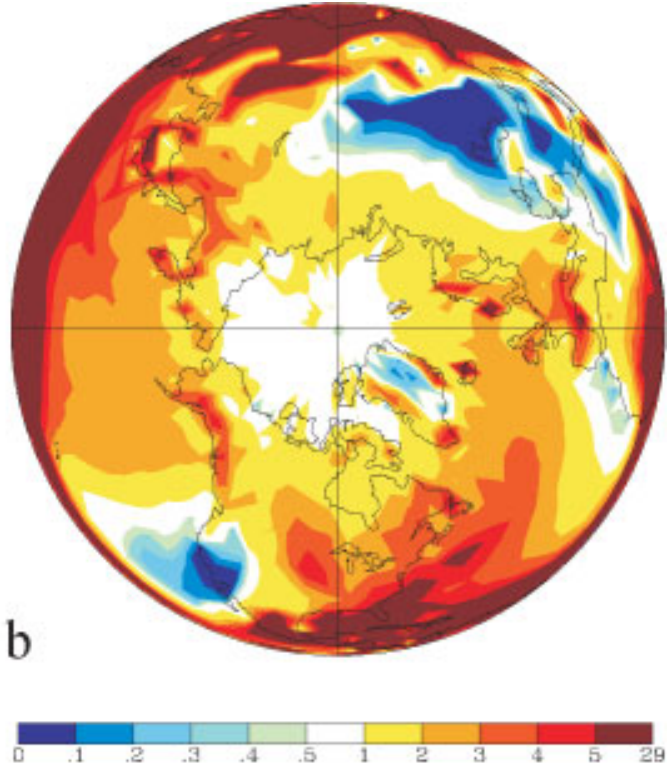

Fig. 2. Modeled minus control run precipitation: (a) DfF; (b) $\mathcal{F} \mathcal{F A}$.

atmospheric model using observed surface conditions (SST and sea-ice concentration). The $\mathrm{CO}_{2}$ experiment was started from the nearly equilibrium state of the control run, which was chosen after about 30 years of integration. $\mathrm{CO}_{2}$ concentration achieved double the initial concentration after about 70 years of integration, and then it remained at this level. The model was integrated for another 75 years. We have evaluated the influence on the coupled system of gradually increasing atmospheric carbon dioxide from the difference between the second (transient $1 \%$ per year $\mathrm{CO}_{2}$ increase) and the first (control) integrations. For this purpose we consider the last 20 years of both integrations where the equilibrium of the $\mathrm{CO}_{2}$ experiment was reached.

\section{RESULTS}

Climate simulation with Q-flux ocean and thermodynamiconly sea-ice model has some limitations. The fully dynamical ocean models allow for circulation changes in the ocean, which include the meridional overturning component, the gyre component, such as the mid-latitude gyres in the North Pacific and North Atlantic, and sub-grid-scale lateral diffusion. The mixed-layer model neglects the effects of possible slowing down of the meridional circulation, which cools the North Atlantic. As a result, the Q-flux model has warmer-than-observed tropical SSTs and cooler-thanobserved high latitude, causing over-extensive sea ice. Because of warm tropical SSTs and over-extensive sea ice, the mixedlayer model is very sensitive to $\mathrm{CO}_{2}$-induced warming, which was noticed in analysis of mixed-layer and fully dynamical ocean simulations by Washington and Meehl (1991). Absence of sea-ice dynamics contributes further to the over-extensive sea-ice cover, not allowing export of sea ice out of the Arctic Ocean. The comparison of model integrations with and without sea-ice dynamics was performed by Pollard and Thompson (1994), who noticed that the overall pattern of sea-ice area bears much less resemblance to reality than that with dynamical ice (Weatherly and others, 1998).

The ability of a climate model to simulate the change of climate caused by doubling $\mathrm{CO}_{2}$ depends in part on how well it reproduces the present climate and its change from winter to summer. In order to assess the simulation capability of the present model, several quantities for the Northern Hemisphere will be shown and compared with observed data.

The unforced control simulation exhibits multi-decadal warming and cooling episodes, with global temperature change up to $0.35^{\circ} \mathrm{C}$, as well as shorter-period fluctuations. The largest variations occur over periods of several decades, but substantial changes often occur within a few years, with the sea-ice changes commonly associated with global temperature change. In the Northern Hemisphere the largest year-to-year variations occur in Baffin and Hudson Bays, in the Barents and East Siberian Seas, in the Sea of Okhotsk and in the Bering and Beaufort Seas. The global surface air temperature has a high correlation (0.82) with the Arctic surface temperature, with the Arctic temperature lagging the global temperature by 2 years. The highest correlation of global temperature and sea-ice extent $(-0.52)$ occurs when the sea-ice extent lags global temperature by 1 year.

Figure 1 shows the observed (Shea and others, 1990) and simulated surface sea-level pressure over the Arctic for December-February (DJF) and June-August (JJA). In winter (Fig. la and b), the North Atlantic low extends northeastwards over the Greenland and Barents Seas. Winter high-pressure systems over the American and Eurasian continents link across the Arctic. Over the North Pacific lies the high-pressure system called the Aleutian low. In the summer (Fig. lc and d), the low-pressure system extends across the Arctic, linking the high-pressure systems in the Pacific and Atlantic. In winter, low precipitation values lie along the high-pressure ridge over the central Arctic (Fig. 2a), while the model shows an increase of precipitation in the central Arctic during summer (Fig. 2b). The annual mean Arctic precipitation minus evaporation is consistent with the European Centre for Medium-range Weather Forecasts analysis field given by Briegleb and Bromwich (1998) (not shown).

Surface air temperature over the Arctic, observed (Rigor and others, 2000) and simulated for DJF and JJA, is shown in Figure 3. Observed surface air temperatures from the International Arctic Buoy Programme/Polar Exchange at the Sea Surface (Rigor and others, 2000) have higher correlations and lower rms errors than previous surface air-temperature fields from land stations and the Russian North Pole drift 
Nazarenko and others: Response of Northern Hemisphere sea ice to greenhouse forcing
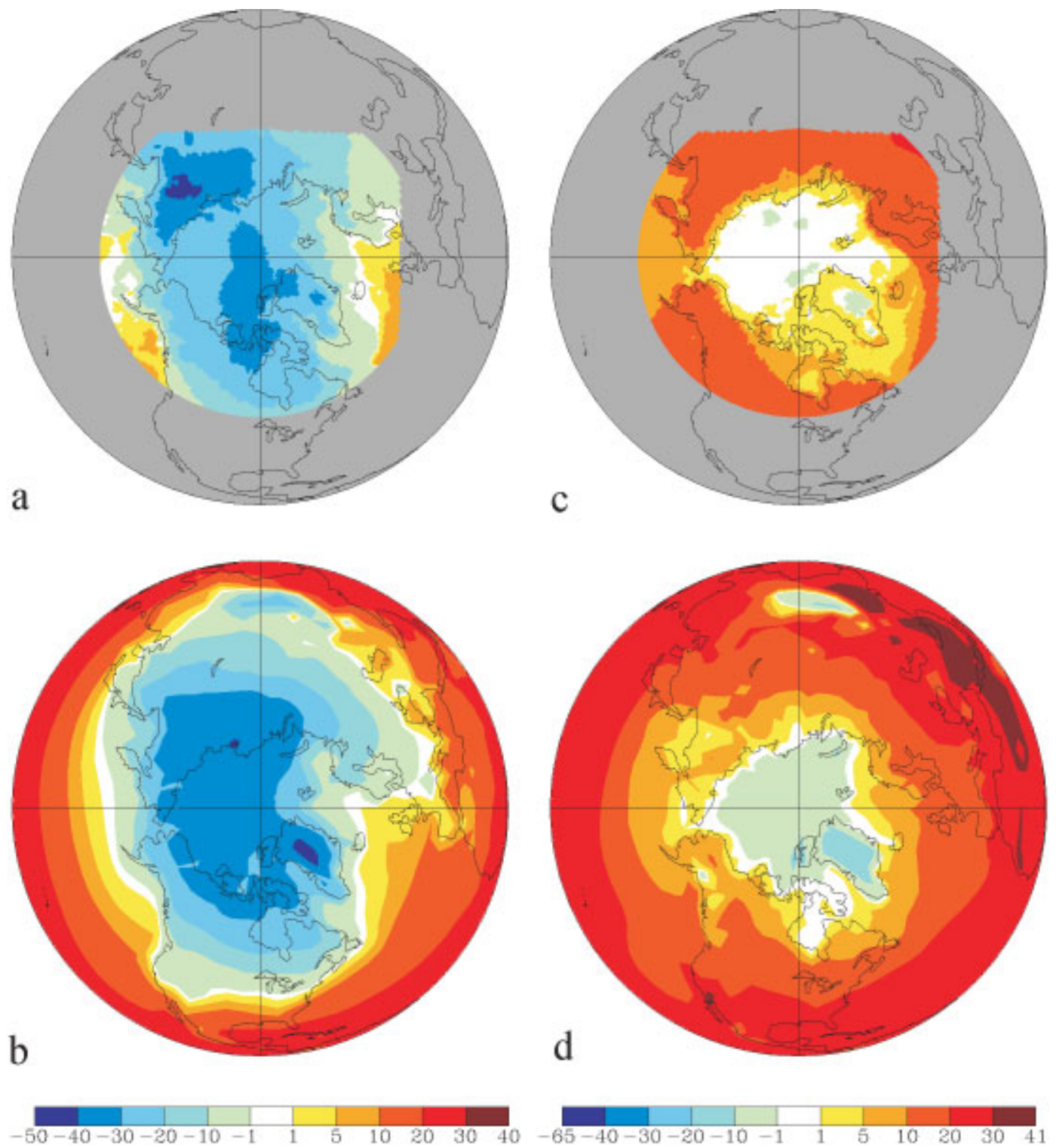

Fig. 3. As Figure 1, but for surface air temperature. Observed fields are derived from the dataset of Rigor and others (2000).
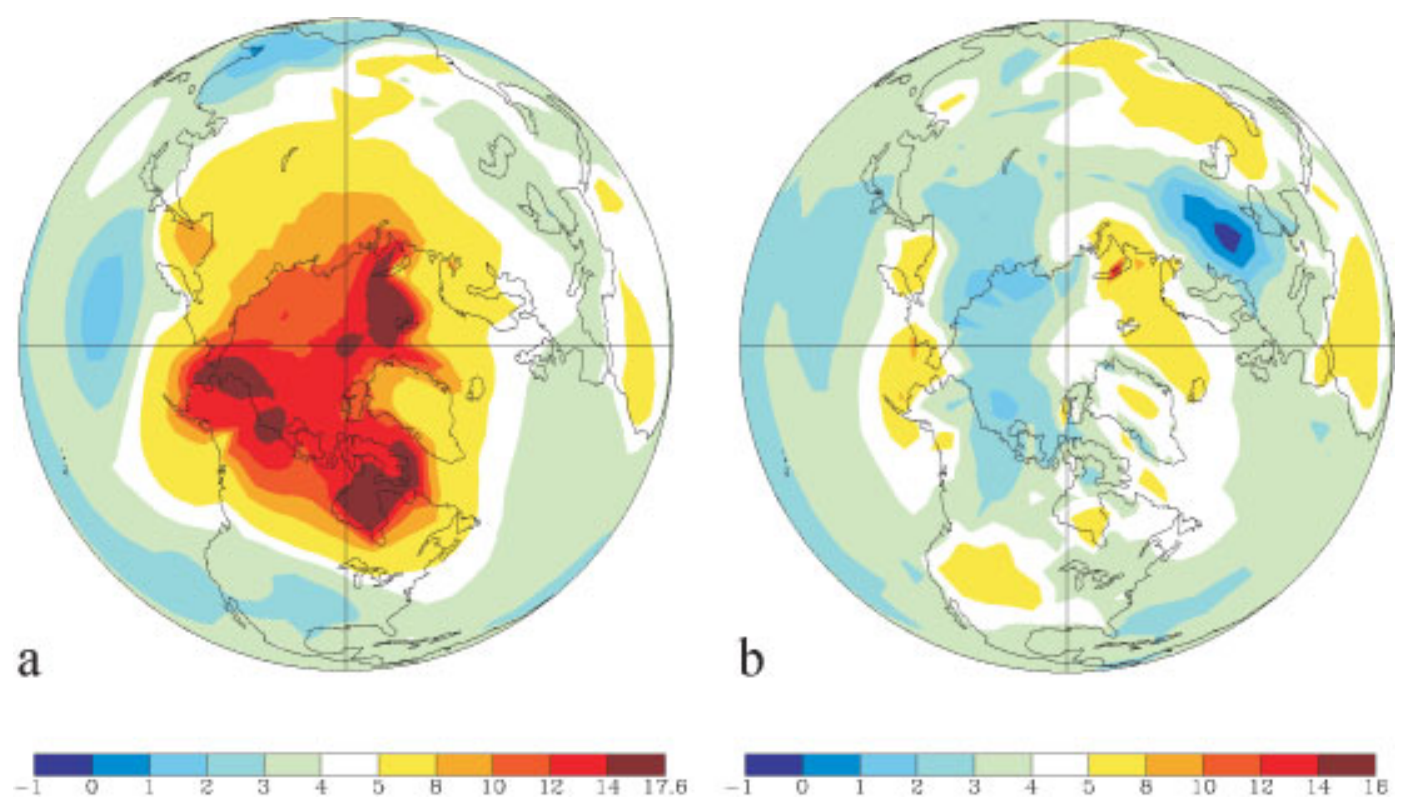

Fig. 4. Surface air-temperature change (greenhouse experiment minus control), averaged over the last 20 years of simulations: (a) $D \mathcal{F F}$; (b) $\mathcal{F} f A$. 

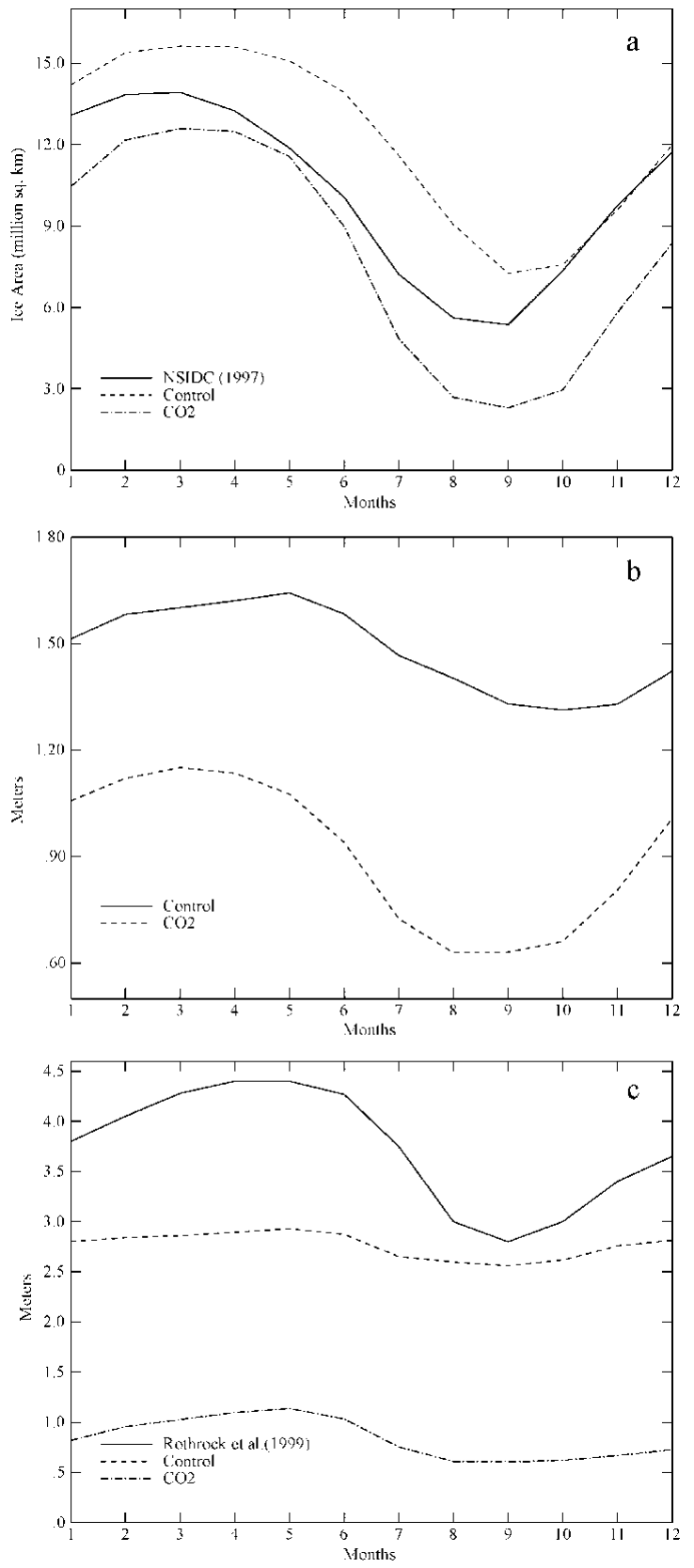

Fig. 5. Mean annual cycle (over last 20 years of integration) of monthly Northern Hemisphere sea ice: (a) ice area; (b) ice thickness; (c) ice thickness for the central Arctic. Observed fields are derived from NSIDC (1997) and Rothrock and others (1999).

stations and provide better temperature estimates, especially during summer in the marginal ice zones. The coldest surface air temperature in DJF is over the Greenland ice cap and the Siberian land where the lowest mean temperatures are below $-40^{\circ} \mathrm{C}$ (Fig. 3a and b). Over the Arctic Ocean, the coldest air is modeled on the northern sides of the Siberian coast and Canadian Archipelago. Relatively warm air penetrates the Arctic from the North Átlantic through the northeastward extension of the Icelandic trough. In summer (Fig. 3c and d), surface air temperature is much higher than in winter, with warm air $\left(>0^{\circ} \mathrm{C}\right)$ around all coastlines and outside of the central Arctic. Nevertheless, the model reproduces surface air temperature a little too low over the central Arctic compared to the data.

The doubled $\mathrm{CO}_{2}$ experiment reveals that the current GISS mixed-layer Q-flux model continues to have high sensitivity with about $4^{\circ} \mathrm{C}$ global warming. This compares with a range of simulated temperature increase of $1.9-5.2^{\circ} \mathrm{C}$ obtained with climate models of this kind (Mitchell and others, 1988). The warming is greatest around sea-ice margins in winter and least over sea ice in summer. There is little seasonal variation in the warming of the tropics. Temperatures increase more over land than over the ice-free ocean. The annual mean warming is greatest at high latitudes, which has been noted in other simulations and has been attributed mainly to sea-ice and snow albedo feedback (Manabe and Stouffer, 1980; Ingram and others, 1989). This feedbacmechanism requires sufficient warming to cause substantial melting of snow and ice at high latitudes. The resulting decrease of albedo then permits further warming, more melting of ice and snow, and so on. The melting of ice and the heat stored in the ocean mixed layer during the summer as a result of $\mathrm{CO}_{2}$-associated tropospheric warming contribute to less sea-ice formation during the following winter and a poleward shift of the ice margin. The mixed-layer ocean continues to release heat at latitudes of ice-free ocean in the doubled $\mathrm{CO}_{2}$ case throughout the winter, as evidenced by the large warming at the ice margins.

This effect is evident in Figure 4 where surface airtemperature changes resulting from doubling of the $\mathrm{CO}_{2}$ are illustrated for DJF and JJA averaged over the last 20 years of simulations. These results are very similar to other model outputs (Schlesinger and Mitchell, 1987; Gordon and Hunt, 1994). The surface air temperature increased by $2-4^{\circ} \mathrm{C}$, with larger warming at high latitudes. In both polar regions, temperature rises of $>10^{\circ} \mathrm{C}$ were obtained during winter owing to the melting of sea ice. The warming over land in the Northern Hemisphere is greater during winter, although higher warming occurs over North America during the summer. It is interesting to notice that the model displays slight cooling (about $-0.5^{\circ} \mathrm{C}$ ) of surface air over Europe. This result indicates that severe regional cold can still occur even under enhanced greenhouse conditions.

The mean (over the last 20 years of integration) of monthly Northern Hemisphere sea-ice areas from Q-flux control and $\mathrm{CO}_{2}$ experiments, as well as from satellite data (NSIDC, 1997), is shown in Figure 5a. The satellite values were interpolated to the model grid. The Northern Hemisphere sea-ice area from the control run is $20-25 \%$ greater than the satellite values in January-September, and it is consistent with the satellite data in October-December (Fig. 5a). The excessive modeled ice cover could partially be explained by the possible underestimation of sea-ice area in the satellite data due to the technical difficulty of distinguishing melt ponds and open water. Sea-ice area decrease resulting from doubling of the $\mathrm{CO}_{2}$ has a maximum of $70 \%$ for the Northern Hemisphere in August, with a smaller decrease in winter. The area-averaged thickness, defined as the area-weighted mean of ice thickness in the ice-covered fraction of each gridcell, is shown in Figure $5 \mathrm{~b}$ for the control and $\mathrm{CO}_{2}$ experiments. The control run reproduces the seasonal cycle of ice thickness with a maximum of $1.6 \mathrm{~m}$ in May and minimum of 1.3 in October. Our Q-flux model shows a small seasonal cycle which can be seen from the comparison of sea-ice thickness in the central Arctic (Fig. 5c). The ice-thickness data from Rothrock and others (1999) represent the modeled seasonal cycle of ice thickness over the central Arctic from an ice-ocean model with a 12-category icethickness distribution (Zhang and others, 1998). This seasonal cycle was modeled over 40 years of data-release 

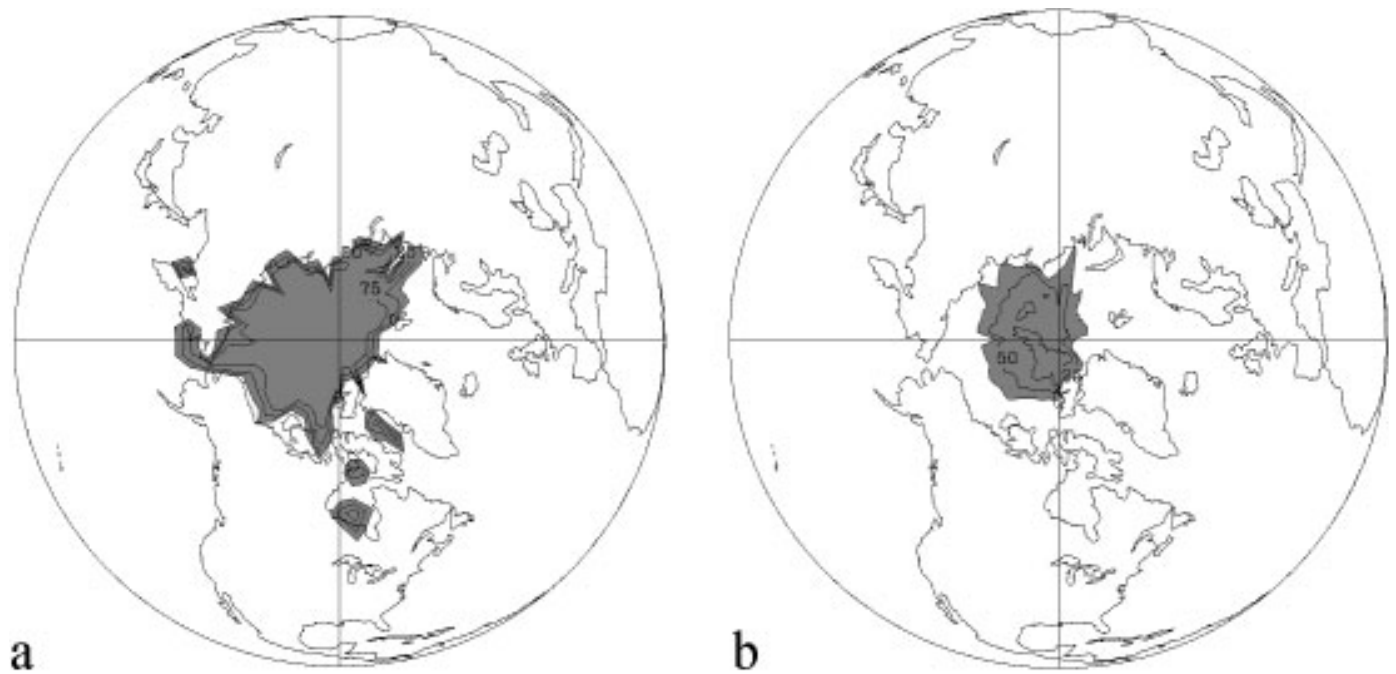

Fig. 6. Monthly mean ice concentration in August from (a) control and (b) $\mathrm{CO}_{2}$ experiments. Shaded areas are concentrations of $>0.25$.

area in the central Arctic. The annual mean ice thickness in the central Arctic (Rothrock and others, 1999) is about $3.5 \mathrm{~m}$, while our control run has an annual mean ice thickness of about $2.75 \mathrm{~m}$ with a small seasonal cycle. The absence of sea-ice dynamics is one limitation of the Q-flux model, which might be a reason for the reduction of the
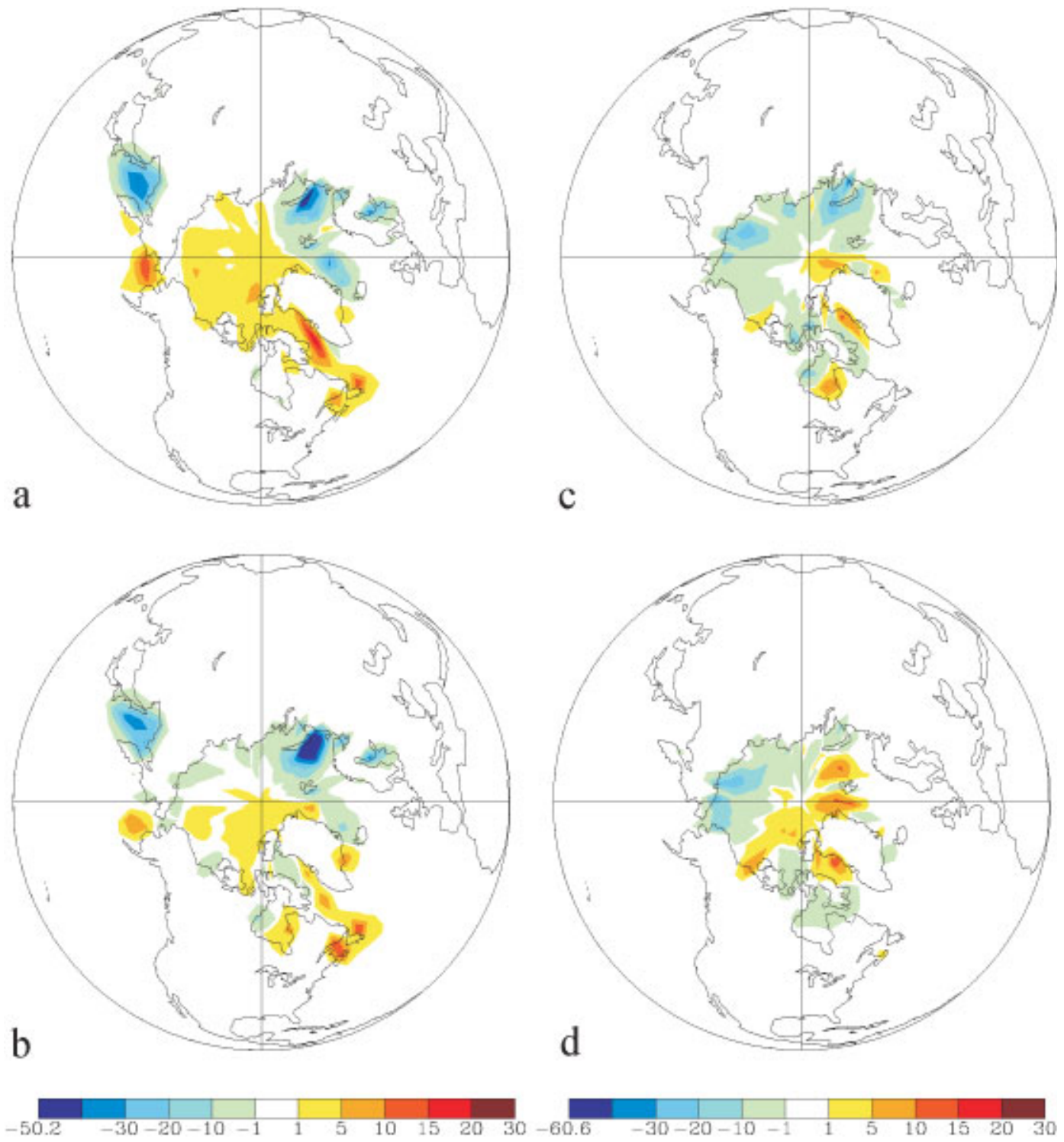

Fig. 7. Observed Northern Hemisphere sea-ice-cover change based on linear trend for 1979-96 (NSIDC, 1997): (a) DecemberFebruary; (b) March-May; (c) June-August; (d) September-November. 

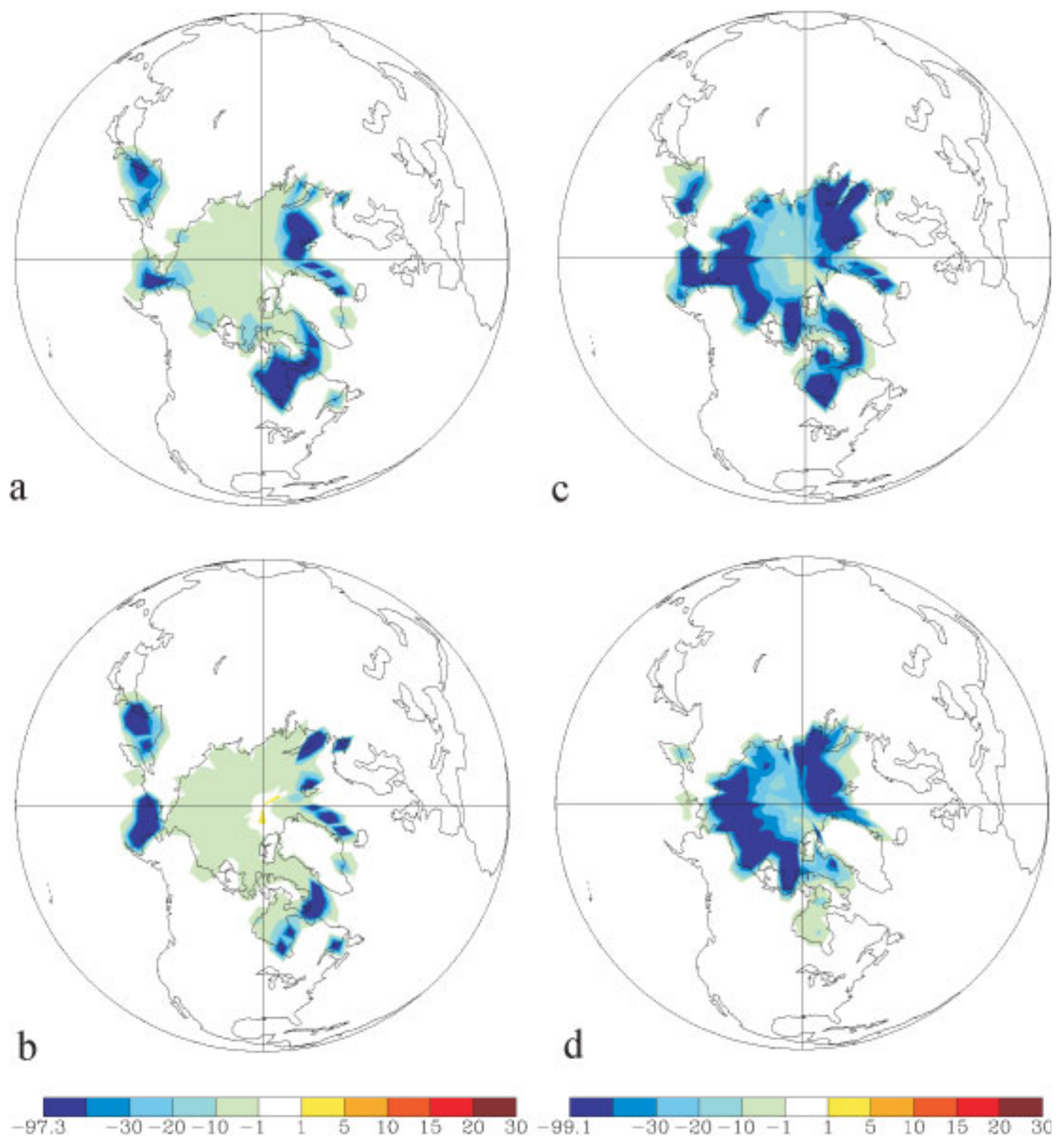

Fig. 8. Northern Hemisphere sea-ice-cover change (greenhouse experiment minus control), averaged over the last 20 years of simulations: (a) December-February; (b) March-May; (c) June-August; (d) September-November.

sea-ice thickness seasonal cycle. Sea-ice thickness decrease resulting from doubling of the $\mathrm{CO}_{2}$ has a maximum of $55 \%$ for the Northern Hemisphere in August. An ice slab has a smaller annual thickness range of roughly $0.5 \mathrm{~m}$, while the thinning in the central Arctic (Fig. 5c) is about $2 \mathrm{~m}$, with maximum decrease of ice thickness in summer $(76 \%)$.

Mean ice concentrations from the 20 year climatology for August are shown in Figure 6 for the control and $\mathrm{CO}_{2}$ experiment. The motionless concentrations form more or less concentric circles centered nearly on the pole, corresponding to the nearly zonal isotherms in the atmosphere. This fact was noticed by Pollard and Thompson (1994) after the comparison simulations with and without ice dynamics. Shaded areas are concentrations of $>0.25$. The control model does not show much retreat of the sea in the Arctic Ocean (Fig. 6a), while the $\mathrm{CO}_{2}$ experiment exhibits extensive reduction of sea-ice concentration in the central Arctic (Fig. 6b). The annual mean sea-ice reduction due to doubled $\mathrm{CO}_{2}$ is about $30 \%$ for the Northern Hemisphere, similar to the results of Pollard and Thompson (1994).

Recent satellite-based observations show a decrease of Northern Hemisphere sea ice since 1978. Various groups of scientists had found from satellite observations and historical records of ice extent that the Arctic sea-ice cover has been shrinking at a rate of about 3\% per decade during recent decades (Maslanik and others, 1996; Cavalieri and others, 1999; Gloersen and others, 1999; Johannessen and others, 1999; Parkinson and others, 1999; Deser and others, 2000). Figure 7 shows the Northern Hemisphere sea-ice-cover change based on linear trend from the satellite data (NSIDC, 1997) from 1979 to 1996. The analysis of satellite data shows a reduction of sea-ice cover every season, with maximum decrease in spring and summer. In summer, a decrease of sea-ice extent was observed in both the Eurasian and Canadian basins of the Arctic, while there is an increase of sea-ice extent north of Greenland and in Baffin Bay, which might be explained by enhancement of sea-ice transport in summer. This pattern of diminishing ice cover east of Greenland, and increasing ice cover west of Greenland, is similar to that reported by Deser and others (2000). The latest sea-ice extent data of the Hadley Centre for Climate Prediction and Research (Bracknell, U.K.) global sea-ice and SST dataset (GISST4.0) show a reduction of sea-ice cover from 1951 to 1998 during fall, winter and spring, with twice as large a reduction during summer. The simple mixed-layer Qflux model reveals a seasonality of sea-ice reduction in the Northern Hemisphere (Fig. 8) consistent with observational data. The summer decrease of sea cover is almost double that 
in winter and spring. In fall the model shows a residual high shrinkage of sea-ice cover, but this is smaller than in summer.

\section{CONGLUSION}

We have investigated the interannual variability of the GISS Q-flux global climate model. This model uses a monthlyvarying mixed-layer depth and specified horizontal heat transports. Natural climatic variability consists of multidecadal warming and cooling periods, with the largest year-to year variations of sea ice in the marginal ice zone and the shelf seas. The overall behavior of the control Q-flux climate model is reasonably consistent with observations.

The sensitivity of a global climate model to an increase of the $\mathrm{CO}_{2}$ content in the atmosphere has considerable spatial and temporal variations. The $\mathrm{CO}_{2}$-induced warming of the surface air is large at high latitudes owing to the poleward retreat of snow cover and sea ice and more stable atmospheric lapse rates. Over the northern polar region, the warming of the surface atmospheric layer of the model is much larger in winter than in summer. The additional heat energy absorbed by the oceans during the warm season delays the appearance of the sea ice. This reduces the thermal insulation effect of the sea ice, enhancing the warming of the surface atmospheric layer.

The Northern Hemisphere sea-ice area from the control experiment is about $20 \%$ greater than the satellite values. The analysis of sea-ice thickness for the central Arctic shows that the control Q-flux model produces a smaller seasonal cycle of ice thickness compared to observations (Rothrock and others, 1999). These problems are presumed to be mainly a result of the omission of sea-ice dynamics.

The experiment yields a reduction of sea-ice area and $55 \%$ thinning of ice in August in the Northern Hemisphere. The annual mean sea-ice shrinkage due to doubled $\mathrm{CO}_{2}$ is about $30 \%$ for the Northern Hemisphere. This is consistent with the results of Pollard and Thompson (1994), where they compare the response of dynamical and motionless sea ice to doubled $\mathrm{CO}_{2}$.

Seasonal variability of the Northern Hemisphere sea-ice cover is consistent with observational data. Both satellite data and the surface-based historical record of sea-ice extent show shrinkage of the Arctic sea-ice cover, with maximum decrease in summer. The greenhouse Q-flux model reveals the largest reduction of sea-ice extent in summer, which is almost double the winter decrease, with residual high shrinkage in fall.

\section{REFERENCES}

Briegleb, B. P. and D. H. Bromwich. 1998. Polar climate simulation of the NCAR CGM3. 7. Climate, 11(6), 1270-1286.

Cavalieri, D. J., C. L. Parkinson, P. Gloersen, J. C. Comiso and H. J. Zwally. 1999. Deriving long-term time series of sea ice cover from satellite passive-microwave multisensor data sets. F. Geophys. Res., 104(C7), $15,803-15,814$.

Deser, C., J. E. Walsh and M. S. Timlin. 2000. Arctic sea ice variability in the context of recent atmospheric circulation trends. F. Climate, 13(3), 617-633.

Gloersen, P., C. L. Parkinson, D. J. Cavalieri, J. C. Comiso and H. J. Zwally. 1999. Spatial distribution of trends and seasonality in the hemispheric sea ice cover: 1978-1996. F. Geophys. Res., 104(C9), 20,827-20,835.

Gordon, H. B. and B. G. Hunt. 1994. Climatic variability within an equilibrium greenhouse simulation. Climate Dyn., 9(4-5), 195-212.

Hansen, J. and 7 others. 1984. Climate sensitivity: analysis of feedback mechanisms. In Hansen, J. E. and T. Takahashi, eds. Climate processes and climate sensitivity. Washington, DC, American Geophysical Union, 130-163. (Geophysical Monograph 29, Maurice Ewing Series 5.)

Hansen, J. and 6 others. 1988. Global climate changes as forecast by Goddard Institute for Space Studies three-dimensional model. 7. Geophys. Res., 93(D8), 9341-9364.

Hansen, J. and 42 others. 1997. Forcing and chaos in interannual to decadal climate change. 7. Geophys. Res., 102(D22), 25,679-25,720.

Houghton, J.T., G. J. Jenkins and J. J. Ephraums. 1990. Climate change: the IPCC scientific assessment. Cambridge, etc., Cambridge University Press.

Ingram, W. J., C. A. Wilson and J. F. B. Mitchell. 1989. Modeling climate change: an assessment of sea ice and surface albedo feedbacks. $\mathcal{F}$. Geophys. Res., 94(D6), 8609-8622.

Johannessen, O. M., E.V. Shalina and M.W. Miles. 1999. Satellite evidence for an Arctic sea ice cover in transformation. Science, 286(5446), 1937-1939.

Kutzbach, J. E. and R. G. Gallimore. 1988. Sensitivity of a coupled atmosphere/mixed layer ocean model to changes in orbital forcing at 9000 years B.P. F. Geophys. Res., 93(D1), 803-821.

Manabe, S. and R. J. Stouffer. 1980. Sensitivity of a global climate model to an increase of $\mathrm{CO}_{2}$ concentration in the atmosphere. 7. Geophys. Res., 85(C10), 5529-5554.

Manabe, S., R. J. Stouffer, M.J. Spelman and K. Bryan. 1991. Transient response of a coupled ocean-atmosphere model to gradual changes of atmospheric $\mathrm{CO}_{2}$. Part I: Annual mean response. 7. Climate, 4(8), 785-818.

Maslanik, J. A., M. C. Serreze and R. G. Barry. 1996. Recent decreases in Arctic summer ice cover and linkages to atmospheric circulation anomalies. Geophys. Res. Lett., 23(13), 1677-1680.

Meehl, G. A., W. M. Washington and T. R. Karl. 1993. Low-frequency variability and $\mathrm{CO}_{2}$ transient climate change. Climate Dyn., 8(3), 117-133.

Mitchell, J. F. B. 1989. The "greenhouse" effect and climate change. Rev. Geophys., 27(1), 115-139.

Mitchell, J. F. B., N. S. Grahame and K. J. Needham. 1988. Climate simulations for 9000 years before present: seasonal variations and effect of the Laurentide ice sheet. F. Geophys. Res., 93(D7), 8283-8303.

National Snow and Ice Data Center (NSIDC). 1997. Passive microwave derived daily polar sea ice concentration time series. Boulder, CO, University of Colorado. Cooperative Institute for Research in Environmental Sciences. National Snow and Ice Data Center, Distributed Active Archive Center.

Parkinson, C. L. and W. M. Washington. 1979. A large-scale numerical model of sea ice. 7. Geophys. Res., 84(Cl), 311-337.

Parkinson, C. L., D. J. Cavalieri, P. Gloersen, H. J. Zwally and J. C. Comiso. 1999. Arctic sea ice extents, areas, and trends, 1978-1996. F. Geophys. Res., 104 (C9), 20,837-20,856.

Pollard, D. and S. L. Thompson. 1994. Sea-ice dynamics and $\mathrm{CO}_{2}$ sensitivity in a global climate model. Atmosphere-Ocean, 32(2), 449-467.

Rigor, I., R. Colony and S. Martin. 2000. Variations in surface air temperature observations in the Arctic, 1979-1997. f. Climate, 13(5), 896-914.

Rind, D., R. Goldberg and R. Ruedy. 1989. Change in climate variability in the 21st century. Climatic Change, 14(1), 5-38.

Rothrock, D. A., Y. Yu and G. A. Maykut. 1999. Thinning of the Arctic seaice cover. Geophys. Res. Lett., 26(23), 3469-3472.

Schlesinger, M. E. and J. F. B. Mitchell. 1987. Climate model simulations of the equilibrium climatic response to increased carbon dioxide. Rev. Geophys., 25(4), 760-798.

Schlesinger, M. E. and Z.-C. Zhao. 1989. Seasonal climate changes induced by doubled $\mathrm{CO}_{2}$ as simulated by the OSU atmospheric GCM/mixedlayer ocean model. 7. Climate, 2(5), 463-499.

Shea, D. J., K. E. Trenberth and R.W. Reynolds. 1990. A global monthly SST climatology. Boulder, CO, National Center for Atmospheric Research. (NCAR Technical Note NCAR-TN-435.)

Washington, W. M. and G. A. Meehl. 1984. Seasonal cycle experiment on the climate sensitivity due to a doubling of $\mathrm{CO}_{2}$ with an atmospheric general circulation model coupled to a simple mixed layer ocean. $\mathcal{F}$. Geophys. Res., 89(D6), 9475-9503.

Washington, W. M. and G. A. Meehl. 1991. Characteristics of coupled atmosphere-ocean $\mathrm{CO}_{2}$ sensitivity experiments with different ocean formulations. In Schlesinger, M. E., ed. Greenhouse-gas-induced climatic change: a critical appraisal of simulations and observations. Amsterdam, Elsevier Science Publishers, 79-110.

Weatherly, J.W., B. P. Briegleb, W. G. Large andJ. A. Maslanik. 1998. Sea ice and polar climate in the NCAR CSM. F. Climate, 11 (6), 1472-1486.

Wetherald, R. T. and S. Manabe. 1986. An investigation of cloud cover change in response to thermal forcing. Climatic Change, 8(1), 5-24.

Wilson, C.A. and J. F. B. Mitchell. 1987. A doubled $\mathrm{CO}_{2}$ climate sensitivity experiment with a GCM including a simple ocean. 7. Geophys. Res., 92(D11), 13,315-13,343.

Zhang, J., D. A. Rothrock and M. Steele. 1998. Warming of the Arctic Ocean by strengthened Atlantic inflow: model results. Geophys. Res. Lett., 25(10), 1745-1748. 